\title{
Habitat Fragmentation Did Not Affect the Composition of Braconid Wasp Communities in Tropical Lowland Forests of Panama
}

\section{Louise A. Rodríguez Scott}

Universidad de Panamá: Universidad de Panama

Enrqiue Medianero ( $\boldsymbol{\nabla}$ enrique.medianero@up.ac.pa )

Universidad de Panamá: Universidad de Panama https://orcid.org/0000-0002-8430-9034

\section{Research article}

Keywords: Braconidae, Forest fragments, Parasitoid, Similarity Index

Posted Date: March 1st, 2022

DOI: https://doi.org/10.21203/rs.3.rs-1272212/v1

License: (c) (i) This work is licensed under a Creative Commons Attribution 4.0 International License.

Read Full License 


\section{Abstract \\ Background}

The forests along the eastern bank of the Panama Canal have been conserved for more than 200 years; however, in the last 171 years, these sites have been pressured by anthropic activities. Studies of the influence of habitat fragmentation on braconid wasp communities in Central America is scarce, showing the existing information gap on these communities required to implement strategic plans for ecosystem sustainability and conservation. This study investigated how fragmentation affects braconid wasp communities in three areas in Panama City: Metropolitan Natural Park, Albrook and Corozal. Two permanent Malaise Traps were installed in the center of each fragment and were reviewed weekly from May 2019 to March 2020. Similarity and fragmentation indices were used to demonstrate the influence of habitat fragmentation on braconid wasp communities.

\section{Results}

There is a decrease in the degree of fragmentation ( $F R A G=6.95$, on a scale of $0-10$ ). A similarity of $99 \%$ was estimated for the composition of wasp community in the fragments studied. Wasp subfamily and morphospecies assemblages were more similar between fragments of Albrook and Metropolitan Natural Park. Richness and abundance of braconid wasps observed were statistically different between the fragments studied.

\section{Conclusion}

Landscapes with an intermediate degree of fragmentation does not influence the composition of braconid wasp communities, reflected by high similarity between communities. Therefore, the fragments studied can be used as stepping stones to maintain remaining populations of braconid wasp communities. Monitoring is recommended to assess the effect of fragmentation on the remaining forests.

\section{Background}

Habitat fragmentation represents one of the most serious threats to global biodiversity (1-6). Global assessments have shown that habitat fragmentation is provoking a decrease in population size and an increased risk of disappearance of many flora and fauna $(7,8)$. More than $50 \%$ of tropical forests have been degraded globally and with the use of satellite images, it is revealed that almost $43 \%$ of the terrestrial surface has been converted from its natural state for anthropogenic purposes $(9,10)$. From 2000 to 2010 , there was a net loss of forest cover of 7 million hectares (ha) per year in the tropical countries of the world (11). In Panama, the forest cover has decreased from 5,245,000 ha in 1947 to 
$2,481,658$ ha in 2019 , which represents $47 \%$ forest cover loss (12). If the fragmentation process continues at an exponential rate, the world's tropical forests could disappear completely (13).

Habitat fragmentation often occurs due to some disturbance mechanism (agriculture, deforestation, urbanization, fires, etc.) or it can be static, as a result of topographic differences (14). As the world's human population continually increases, urban areas are growing rapidly and threaten the habitat of native species of flora and fauna. Studies investigating the influence of habitat fragmentation on biodiversity and the risk of species extinction are of the utmost importance and have been a main focus of biodiversity conservation research (15-20). For instance, the abundance of dung beetle decreased with increased urban land cover (21). Both common and rare species of social wasps are threatened by forest fragmentation in Central Amazon (22).

In tropical forests, evidence indicates that one of the taxa that respond faster to environmental changes are insects $(23,24)$. Insects play important roles in almost all trophic levels; therefore, it is important to understand the response of these organisms to fragmentation. Within this taxon, parasitoids as a group may be used to assess the effects of habitat fragmentation because they play an ecological role in regulating populations of other insects due to prey denso-dependence (13). González and Ruíz (25) proposed the use of braconid wasps (parasitoids) as indicators in a study of the biological diversity of deciduous forests and in the evaluation and monitoring the effects of anthropogenic activities on ecosystems. Braconid wasps are regulatory agents of various groups of herbivorous insects that indicate the presence or absence of other species through the food chain (26). Most braconid wasps are endo or exo parasitoids which feed on the larval stages of Coleoptera, Diptera and Lepidoptera (27). This makes parasitoids of Braconidae good biological indicators of habitat disturbances (25).

To establish more direct links with ecosystem processes, there is a need to investigate patterns of functional trait and taxonomic diversity with biological indicators. Fragmentation experiments are useful tools used to provide clear evidence of the strong and typically degrading impacts of biodiversity loss (28). Studies on the influence of habitat fragmentation on braconid wasp communities in lowland forests of Central America is scarce, portraying the existing information gap on these communities required to implement strategic plans for ecosystem sustainability and conservation. It is expected that landscapes with an intermediate degree of fragmentation will cause separation of braconid wasp communities which is reflected by a low similarity between communities. This research study contributes to the construction of baseline data by evaluating the vulnerability of braconid wasp communities leading to strategic plans for the sustainability and conservation of ecosystems. We sought to determine how habitat fragmentation may affect braconid wasp communities in fragmented lowland forest locations in Panama using similarity and fragmentation indices.

\section{Results}

Taking into consideration the distance between habitat fragments, the density of each and the number of habitats, the value of FRAG obtained in this research was 6.95 , which shows a decrease in the degree of 
fragmentation. Based on this value, the three fragments studied were found to be in a state of transitional fragmentation where the fragments are considered to be partially conserved.

A total of 1697 individual wasps belonging to 77 morphospecies and 16 subfamilies were recorded. Of the 1697 individuals, approximately $39 \%$ were present in the PNM fragment, $36 \%$ in the fragment of COR and $25 \%$ in the fragment of ALB (Table 1). Among the three fragments, Rogadinae was found to be the most abundant subfamily with 456 individual wasps, followed by Alysiinae with 391 individual wasps, Adeliinae with 254 individual wasps, Doryctinae with 168 individual wasps, Aphidiinae with 154 individual wasps and Microgastrinae with 108 individual wasps. In the PNM fragment, 664 individual wasps and 14 subfamilies were observed (Table 1); with the most abundant subfamily being Adeliinae with 119 individual wasps, followed by Doryctinae with 114 individual wasps, Rogadinae with 93 individual wasps, Alysiinae with 89 individual wasps and Microgastrinae with 85 individual wasps (Fig. 2). In the COR fragment, 603 individual wasps and 13 subfamilies were observed (Table 1); with the most abundant subfamily being Alysiinae with 268 individual wasps, followed by Rogadinae with 153 individual wasps, Aphidiinae with 53 individual wasps and Adeliinae with 48 individual wasps (Fig. 2). In the ALB fragment, 430 individual wasps and 16 subfamilies were observed (Table 1); with the most abundant subfamily being Rogadinae with 188 individual wasps, followed by Adeliinae with 87 individual wasps, Alysiinae with 34 individual wasps and Aphidiinae with 27 individual wasps (Fig. 2).

Table 1

Numbers of subfamilies, morphospecies and individuals of braconid wasps in the three fragments studied during the years 2019-2020. The results indicate a greater number of morphospecies in Metropolitan Natural Park (PNM), of subfamilies in Albrook (ALB) and of individuals in Corozal (COR).

\begin{tabular}{|lllll|}
\hline Site & No. of morphospecies & No. of subfamily & No. of individuals & $\%$ of individuals \\
\hline PNM & 56 & 14 & 664 & 39.1 \\
COR & 44 & 13 & 603 & 35.5 \\
ALB & 52 & 16 & 430 & 25.3 \\
\hline
\end{tabular}

Among the three fragments, the most abundant morphospecies belonged to the subfamilies Rogadinae (M 112 y M1), Adeliinae (M 117), Microgastrinae (M 118), Aphidiinae (M 130) and Alysiinae (M 152), respectively (Table 2 ). The aforementioned morphospecies account for approximately $65 \%$ of the total individual wasp separated as morphospecies. In the PNM fragment, the most abundant morphospecies belonged to the subfamilies Rogadinae (M 117) and Microgastrinae (M 118) with 80 individual wasps for each, followed by Alysiinae (M 152) with 75 individual wasps, Doryctinae (M 128) with 73 individual wasps and Aphidiinae (M 130) with 73 individual wasps (Table 2). In the COR fragment, the most abundant morphospecies belonged to the subfamilies Rogadinae ( $M$ 112, M 1 and M 29) with 387 individual wasps and Aphidiinae (M 113) with 32 individual wasps (Table 2). In the ALB fragment, the most abundant morphospecies belonged to the subfamilies Rogadinae (M 1, M117, M5 and M2) with 215 individual wasps and Adelinae (M 116) with 21 individual wasps (Table 2). 
Table 2

Abundance and relative abundance of morphospecies in the three fragments studied during the years 2019-2020. The table shows $95 \%$ of the data for the total individual wasps found.

\begin{tabular}{|c|c|c|c|c|}
\hline Morphospecies no. (Subfamily) & Total & ALB & COR & PNM \\
\hline 112 (Rogadinae) & 286 & 20 & 265 & 1 \\
\hline 1(Rogadinae) & 230 & 91 & 93 & 46 \\
\hline 117 (Adeliinae) & 162 & 53 & 29 & 80 \\
\hline 118 (Microgastrinae) & 97 & 16 & 1 & 80 \\
\hline 130 (Aphidiinae) & 91 & 16 & 21 & 54 \\
\hline 128 (Doryctinae) & 89 & 12 & 4 & 73 \\
\hline 152 (Alysiinae) & 89 & 11 & 3 & 75 \\
\hline 113(Aphidiinae) & 63 & 11 & 32 & 20 \\
\hline 5 (Rogadinae) & 60 & 40 & 20 & 0 \\
\hline 116 (Adeliinae) & 59 & 21 & 12 & 26 \\
\hline 2 (Rogadinae) & 40 & 31 & 5 & 4 \\
\hline 119 (Icheutinae) & 40 & 11 & 7 & 22 \\
\hline 4 (Rogadinae) & 39 & 10 & 24 & 5 \\
\hline 3 (Rogadinae) & 34 & 8 & 3 & 23 \\
\hline 68 (Braconinae) & 22 & 0 & 14 & 8 \\
\hline 121 (Cheloninae) & 18 & 3 & 12 & 3 \\
\hline 139 (Adeliinae) & 17 & 7 & 2 & 8 \\
\hline 120 (Adeliinae) & 16 & 6 & 5 & 5 \\
\hline 137 (Alysiinae) & 16 & 3 & 0 & 13 \\
\hline 144 (Doryctinae) & 15 & 3 & 0 & 12 \\
\hline 153 (Hormiinae) & 15 & 3 & 2 & 10 \\
\hline 19 (Miracinae) & 14 & 1 & 2 & 11 \\
\hline 138 (Doryctinae) & 14 & 3 & 4 & 7 \\
\hline 140 (Rogadinae) & 12 & 1 & 4 & 7 \\
\hline 51 (Hormiinae) & 11 & 9 & 0 & 2 \\
\hline 52 (Hormiinae) & 11 & 1 & 8 & 2 \\
\hline
\end{tabular}




\begin{tabular}{|lllll|}
\hline Morphospecies no. (Subfamily) & Total & ALB & COR & PNM \\
\hline 154 (Rogadinae) & 10 & 1 & 3 & 6 \\
\hline 50 (Rogadinae) & 9 & 1 & 3 & 5 \\
151 (Doryctinae) & 9 & 2 & 1 & 6 \\
20 (Doryctinae) & 8 & 3 & 2 & 3 \\
66 (Braconinae) & 8 & 2 & 0 & 6 \\
31 (Cheloninae) & 6 & 2 & 1 & 3 \\
\hline
\end{tabular}

The results obtained by means of the Kruskal-Wallis test determined that richness $(\mathrm{H}=8.22, \mathrm{gl}=2$, $\mathrm{p}=0.015)$ and abundance $(\mathrm{H}=12.95, \mathrm{gl}=2, \mathrm{p}<0.05)$ of braconid subfamilies observed were statistically different between the fragments. The results obtained by means of the Kruskal-Wallis test determined that richness $(H=6.053, g l=2, p<0.05)$ and abundance $(H=12.95, g l=2, p<0.05)$ of braconid morphospecies observed were statistically different between the fragments.

In the correspondence analysis (CA), 100\% cumulative percentage was explained for both morphospecies and subfamilies in the first two axes. A total inertia of 0.286 was calculated for braconid subfamilies and a total inertia of 0.469 for braconid morphospecies. Wasp assemblages (both morphospecies and subfamilies) were more similar between the ALB and PNM fragment. CA exhibited distinct clustering in the three fragments, as depicted in Fig. 3 for subfamilies. CA demonstrated that the subfamily Euphorinae was only present in the fragment of ALB and Meteorinae was present in the remnants of ALB and COR.

Of the 16 subfamilies, 12 were shared between all fragments studied, two between the ALB and PNM fragments, and one between the ALB and COR fragments (Fig. 4). One subfamily was registered in the fragment of ALB which was not shared between the fragments studied. Of the 77 morphospecies, 29 were shared between all fragments, 11 between the ALB and PNM fragments, three between the COR and PNM fragments and three between the ALB and COR fragments (Fig. 5). Nine registered morphospecies were only found in the ALB fragment, nine different morphospecies were only found in the COR fragment and 13 different morphospecies were found in the PNM fragment, all of which were not shared between the fragments.

According to the Diserud-Odegaard Index, a similarity of 0.9922 (99\%) was estimated for subfamily composition in the fragments studied. Likewise, a similarity of $0.9924(99 \%)$ was estimated for morphospecies composition in the fragments studied. These results depicted similar subfamily and morphospecies composition within and between the fragments studied.

\section{Discussion}


Based on the fragmentation index, using fragment size and distance, we found that braconid wasp communities in fragmented lowland tropical forests of Panama are still very similar, both at the subfamily and morphospecies level. For the effects of intermediate fragmented forests in a state of transitional fragmentation, the composition of braconid wasp communities is not influenced by the process of fragmentation in partially conserved habitat fragments in tropical lowland forests in Panama. The fragments studied are considered to be areas large enough to maintain the biodiversity of wasp communities. The results of this study are consistent with those obtained by Valdez (2018) and RuizGuerra et al. (2015). Ruiz-Guerra et al. (2015) demonstrated that Braconidae communities are very similar in the remnants of conserved tropical forests and secondary forests of Mexico. Valdez (2018) depicted that butterfly communities are very similar in lowland tropical forests of Panama. In the study by Valdez (2018), three of the four habitat fragments compared correspond to those used in the present study. The results of Valdez (2018), indicated that when these three sites were compared, a similarity of $97 \%$ was obtained for the butterfly community. There are two proposed explanations; the first being that fragmentation of the lowland forests studied is recent and the composition of butterfly and wasp communities still present high similarities. The second explanation stems from the species' dispersal ability; since these taxa have the ability to fly, these organisms are able to move freely between fragments and as a result maintain high similarities between communities.

Richness and abundance of braconid subfamilies were statistically different between the fragments studied. The higher richness of braconid wasps found in the fragment of ALB can be explained by the heterogeneous vegetation, composed of open grassland, stubble, border vegetation and secondary forests in this fragment. The higher abundance and heterogeneity in the fragment of PNM can be explained by its proximity to a source; such as the remainder of the PNM. Both fragments offer a wide range of microhabitats for organisms, allowing the survival of more individuals and increasing the availability and diversity of hosts (Yamamoto et al. 2007; Graça and Somavilla 2018). Although the fragmentation index suggests that the process of fragmentation is not affecting the fragments studied, the low richness in the fragment of COR demonstrates the introduction of biodiversity loss due to the process of fragmentation. This highlights the importance of maintaining continuous forests close to other remnants and the need to conserve fragments which provide various habitats for maintenance of species diversity.

The theory provided by the finding of braconid wasp communities is that of metapopulations (Hanski and Gilpin 1997), which assumes that species are distributed over a heterogenous space and not all territories are habitable for each species; as seen with the subfamilies of Euphorinae, Braconinae, Helconinae and Meterorinae. The fragments studied were divided into remnants/patches at a given moment primarily due to the effects of urbanization and industrialization, which separated the populations of braconid wasps forming their metapopulations. The model of the theory that supports this finding is that of patched populations (Hanski and Gilpin 1997), where there are similar patches without clear distinction between sources and sinks. Two suggestions for which there is no distinction may be that the fragments have the same probability of being colonized by braconid wasps due to their dispersal ability and all fragments studied were of similar size. The fragments studied are considered to be areas 
large enough to keep the metapopulations of wasps in equilibrium. However, it would be necessary to prove how the dispersal dynamics of braconid wasps is carried out among fragments to prove that the fragments are indeed patched populations and determine the minimum critical size of the ecosystem to preserve the diversity and composition of species.

Taking this into account, effective planning for the conservation and preservation of the fragments studied require learning and adaptation. A substantial set of theoretical and practical guides have been developed to maintain biodiversity and ecosystem function (Margules and Sarkar 2007), as well as operational models that use these guides for systematic conservation (Knight et al. 2006; Fig. 6). With the aid of the operational model for conservation planning by Knight et al. (2006), it is suggested that the fragments be considered as stepping stones. Stepping stones can improve the persistence of metapopulations allowing the flow of individuals between fragments, ensuring the exchange of stochastic local extinction and recolonization (Sawchik et al. 2002). The preservation of these fairly conserved fragments, with heterogenous vegetation, can favor the presence of organisms by offering various microhabitats to ensure the viability of metapopulations. Baum et al. (2004) showed that a matrix can determine if, and to what extent, corridors and stepping stones, increase the connectivity of a landscape for the survival of species using Prokelisia crocea and Spartina pectinata as indicators. Spatial configuration is particularly important for regional dynamics and must be taken into account in management plans. Small and medium fragments play a fundamental role; in such a way that it is necessary to identify and preserve these fragments.

\section{Conclusions}

The results of this study indicate that landscapes with an intermediate degree of fragmentation does not influence the composition of braconid wasp communities. This finding was interpreted as an indication that the composition of wasp communities still present high similarities and that a species' dispersal ability plays a major role in whether fragmentation affects their composition.

Future studies could analyze genetic variation of species in relationship to population size and environmental variables or study trophic interactions complementing the results obtained in order to determine the internal dynamics (interspecific and intraspecific relationships) in habitat fragments. In addition, annual inventories to assess the real change in braconid wasp communities or other organisms could provide critical monitoring of the effects of habitat fragmentation. These results can help to increase the understanding of the influence of habitat fragmentation on braconid wasp communities in Panama to develop successful conservation strategies. This would make it possible to address the question of the effect of fragmentation on the braconid wasp species.

\section{Methods}

\section{Study sites}


The three selected study sites in Panama City were Metropolitan Natural Park (PNM), public land in the town of Albrook (ALB) and public land in the town of Corozal (COR) (Fig. 1). The PNM fragment is situated $8^{\circ} 59^{\prime} 41.55^{\prime \prime} \mathrm{N}$ and $79^{\circ} 32^{\prime} 35.22^{\prime \prime} \mathrm{W}$ with an area of approximately 18.12 ha and a perimeter of $1756.07 \mathrm{~m}$. Vegetation is characterized as a mixture of tropical humid forest and lowland tropical dry forest, with few areas of stubble and grasslands, and a well-defined stratum. The ALB fragment is situated $8^{\circ} 58^{\prime} 37.49^{\prime \prime} \mathrm{N}$ and $79^{\circ} 33^{\prime} 43.82^{\prime \prime} \mathrm{W}$ with an area of approximately 34.79 ha and a perimeter of $5,003.88 \mathrm{~m}$. Vegetation is characterized as heterogenous, composed of open grasslands, stubble and secondary forests. The COR fragment is situated $8^{\circ} 59^{\prime} 19.34^{\prime \prime} \mathrm{N}$ and $79^{\circ} 34^{\prime} 11.83^{\prime \prime} \mathrm{W}$ with an area of approximately 56.31 ha and a perimeter of $3,028.55 \mathrm{~m}$. Vegetation is characterized as herbaceous with late secondary forest and some open areas. The selected fragments are close in proximity to each other, which guarantees that the results obtained are effects of the fragmentation process of an original matrix and not the natural result caused by the distances between them. The distance between the fragments of ALB and COR is $1,129.86 \mathrm{~m}$. The distance between the fragments of COR and PNM is $2,565.40 \mathrm{~m}$. The distance between the fragments of ALB and PNM is 2,329.31 m.

The study sites form part of a biological corridor that runs along the eastern bank of the Panama Canal (29). In accordance with the UNESCO classification, the three study sites are characterized as lowland tropical semi-deciduous forests. The three sites present annual average temperatures of $26.4^{\circ} \mathrm{C}$, with an annual average precipitation between 1501 to $1800 \mathrm{~mm}$ and altitudes between 20 to 150 masl. The forests along the eastern bank of the Panama Canal have been conserved for more than 200 years; however, in the last 171 years, these sites have been pressured by anthropic activities (30). One of the first anthropic impact along the banks of the Panama Canal was the construction of Panama's railway in 1850. The second anthropic impact along the banks of the Panama Canal was the construction of the French Canal in 1881. Nevertheless, the greatest anthropic impact started in the 1900's when the forests along the eastern bank of the Panama Canal were intervened by military bases (30). During this time, the remaining fragments maintained advanced secondary forest vegetation. In the last 50 years, these sites have been anthropically pressured due to the construction of neighborhoods along the banks of the Panama Canal (30). The COR fragment has been used for Panama government security training activities. The ALB fragment has minimal human traffic; however, it contains a water reservoir at the peak of the fragment. The PNM fragment is along a hiking trail in a protected area but with visitor traffic (31).

\section{Sampling protocol}

Two permanent lightweight Malaise Trap, Townes Style separated by approximately $200 \mathrm{~m}$ were installed in the center of each fragment and wasp samples were collected weekly from May 2019 to March 2020. The traps were made with organza fabric, with dimensions of $5.8 \mathrm{ft}$ tall by $5.4 \mathrm{ft}$ long, and contained a polyethylene collector bottle with $95 \%$ alcohol at its highest end (32). This is a trap designed to collect fast-flying insects whose behavior is to fly upwards when it touches a surface. The Malaise Trap, Townes Style has been widely used in braconid wasps diversity studies in Central America and the world (33-37). A reasonable flat, log-less area of approximately $2 \mathrm{~m}^{2}$ was chosen for the placement location of each trap. The collection bottle was placed facing the magnetic north and half-filled with $95 \%$ ethanol. The 
traps were placed in open areas which served as insect corridors. To exclude the edge effect, a safety distance of approximately $200 \mathrm{~m}$ was defined from the border of each fragment towards the center. Samples were collected every 7 days; resulting in a sampling effort of 44 weeks per trap.

Sample collection followed the methodology established by D. Windsor (38), which has been used to monitor insect communities in the Barro Colorado Island for more than 20 years. Samples were taken to the Master's degree laboratory at the University of Panama, where braconid specimens were separated from the rest of the sample and placed in vials of one dran with $95 \%$ ethanol. All braconid individuals were mounted on entomological pins, number 2 or 3 . Braconid individuals were first sorted as morphospecies (M) using the method of Oliver and Beattie (39). Oliver and Beattie (39) demonstrated that comparisons can be made using morphospecies assemblages as long as each contain a unique identification. Samples were then identified to subfamily level using the Sharkey and Campos taxonomic key from the book Aguilar et al. (40) and the manual by Sharkey et al. (26).

\section{Statistical Analyses}

The degree of fragmentation was evaluated using the fragmentation index (41), as given by Eq. (1):

\section{FRAG $=$ total habitat area/(number of fragments*dispersion of fragments)}

where dispersion of fragments is $2 d_{c}(\lambda / \pi), d_{c}$ is the mean distance from a fragment (its center or centroid) to the closest fragment, and $\lambda$ is the mean density of fragments which is calculated by (number of fragments/total surface of the study area in ha) $x 100$. The ranges of variation of the fragmentation index (FRAG) for forests were from 0 to 10 . Values that are close to 0 show maximum fragmentation and values that are above 10 show minimum fragmentation.

For analysis of the data, all samples were pooled over time, resulting in one sample per site. A KruskalWallis test was performed using the program STATISTICA (42), to determine differences between the number of individuals registered in each study site. Correspondence analysis (CA) calculated by the program XL-Stat (43) was used to characterize the braconid community based on the number of individuals and site. A comparison of the composition of the braconid community was calculated using formula for the Multiple Similarity Index by Diserud and Odegaard (44), as given by the Eq. (2):

$$
\mathrm{C}_{\mathrm{S}}^{\mathrm{T}}=\frac{\mathrm{T}}{\mathrm{T}-1}\left(1-\frac{\mathrm{S}_{\mathrm{T}}}{\sum_{\mathrm{i}} \mathrm{a}_{\mathrm{i}}}\right)
$$

where $a_{i}$ is the number of species in site $A_{i}, T$ is the number of sites and $\mathrm{S}_{\mathrm{T}}=\sum_{i} a_{i}-\sum_{i<j} a_{i j}+\sum_{i<j<k} a_{i j k} \cdots, \mathrm{a}_{\mathrm{ij}}$ is the number of species shared by sites $\mathrm{A}_{\mathrm{i}}$ and $\mathrm{A}_{\mathrm{j}}$; and 
$a_{i j k}$ is the number of species shared by sites $A_{i}, A_{j}$ and $A_{k}$, etc. The multiple similarity index takes into consideration the information of species shared by two or more sites and avoids the problem of covariance between pairwise similarities (44), reducing the probability of Type II errors.

\title{
List Of Abbreviations
}

\author{
ALB \\ Albrook \\ CA \\ Corresponding Analysis \\ COR \\ Corozal
}

FRAG

Fragmentation Index

M

Morphospecies

M_\#

Morphospecies number

PNM

Metropolitan Natural Park

\section{Declarations}

\section{Ethics approval and consent to participate}

Not applicable

Consent for publication

Not applicable

\section{Availability of data and materials}

The datasets used and/or analyzed during the current study are available from the corresponding author on reasonable request.

\section{Competing interests}

The authors declare that they have no competing interests.

\section{Funding}


This research was funded by Secretaría Nacional de Ciencia, Tecnología e Innovación (SENACYT), Sistema Nacional de Investigación (SNI) and the University of Panama (UP).

\section{Author contributions}

All authors contributed to the study conception and design. Material preparation, data collection and analysis were performed by Louise Rodriguez. The first draft of the manuscript was written by Louise Rodriguez and all authors commented on previous versions of the manuscript. All authors read and approved the final manuscript.

\section{Acknowledgments}

To the University of Panama, Secretaría Nacional de Ciencia Tecnología e Innovación (SENACYT) and Sistema Nacional de Investigación (SNI) for providing funds and resources to carry out research activities. To MIAmbiente (Ministry of Environment) and Metropolitan Natural Park for issuing collection permits. To Marcelo Mack and JeanCarlos Abrego for their help with sample collection.

\section{References}

1. Fahrig L. Effects of Habitat Fragmentation on Biodiversity. Annu Rev Ecol Evol Syst. 2003;34:487515.

2. Fontúrbel FE. Evaluation of the Loss of the Chaqueño Dry Forest Coverage in Torotoro's Municipality and in Torotoro National Park (Potosí, Bolivia), through Remote Sensing. Ecol Apl. 2007;6(1,2):5966.

3. Rands MRW, Adams WM, Bennun L, Butchart SHM, Clements A, Coomes D, et al. Biodiversity conservation: Challenges beyond 2010. Science. 2010;80-:329:1298-303.

4. Zurita MEC. Análisis de la fragmentación en el Parque Nacional Cerro Azul Meámbar (PANACAM). 2014.

5. Macedo-Reis LE, Quesada M, de Siqueira Neves F. Forest cover drives insect guild diversity at different landscape scales in tropical dry forests. For Ecol Manage. 2019;443:36-42.

6. Rogan JE, Lacher TE. Impacts of Habitat Loss and Fragmentation on Terrestrial Biodiversity. In: Reference Module in Earth Systems and Environmental Sciences. Elsevier Inc; 2018. pp. 1-18.

7. Mas J-F, Sandoval JC. Analysis of landscape fragmentation in the Petenes protected area, Campeche, Mexico. Investig Geográficas. 2000;(6):42-59.

8. Tittensor DP, Walpole M, Hill SLL, Boyce DG, Britten GL, Burgess ND, et al. A mid-term analysis of progress toward international biodiversity targets. Sci (80-). 2014;346(6206):241-4.

9. Chazdon RL, Harvey CA, Komar O, Griffith DM, Ferguson BG, Martínez-Ramos M, et al. Beyond reserves: A research agenda for conserving biodiversity in human-modified tropical landscapes. Biotropica. 2009;41(2):142-53. 
10. Barnosky AD, Hadly EA, Bascompte J, Berlow EL, Brown JH, Fortelius M, et al. Approaching a state shift in Earth's biosphere. Nature. 2012;486(7401):52-8.

11. FAO. El estado de los bosques del mundo. 2016.

12. SINIA. Diagnóstico de cobertura de Bosques y Otras Tierras Boscosas en la República de Panamá: año 2019 [Internet]. 2020 [cited $2020 \mathrm{Jul}$ 30]. Available from:

https://www.sinia.gob.pa/index.php/cobertura-boscosa/ano-2019/a-nivel-nacional.

13. Haddad NM, Brudvig LA, Clobert J, Davies KF, Gonzalez A, Holt RD, et al. Habitat fragmentation and its lasting impact on Earth's ecosystems. Appl Ecol. 2015.

14. Franklin AB, Noon BR, George TL. What is habitat fragmentation? Stud Avian Biol. 2002;(25):20-9.

15. Laurance WF. Comparative Responses of Five Arboreal Marsupials to Tropical Forest Fragmentation. J Mammal. 1990;71(4):641-53.

16. Conner RN, Rudolph DC. Forest habitat loss, fragmentation, and red-cockaded woodpecker populations. NCASI Tech Bull. 1991;103(3):446-57.

17. Newmark WD. Tropical Forest Fragmentation and the Local Extinction of Understory Birds in the Eastern Usambara Mountains, Tanzania. Conserv Biol. 1991;5:67-78.

18. Didham RK, Hammond PM, Lawton JH, Eggleton P, Stork NE. Beetle species responses to tropical forest fragmentation. Ecol Monogr. 1998;68(3):295-323.

19. Bergman KO, Dániel-Ferreira J, Milberg P, Öckinger E, Westerberg L. Butterflies in Swedish grasslands benefit from forest and respond to landscape composition at different spatial scales. Landsc Ecol. 2018;33:2189-204.

20. Andrade AC, Franzini LD, Mesquita DO. Assessing the effect of urbanization on tropical forest dwelling teiid lizards. Ecol Indic. 2019;99:225-9.

21. Salomão RP, Alvarado F, Baena-Díaz F, Favila ME, lannuzzi L, Liberal CN, et al. Urbanization effects on dung beetle assemblages in a tropical city. Ecol Indic. 2019;103:665-75.

22. Graça MB, Somavilla A. Effects of forest fragmentation on community patterns of social wasps (Hymenoptera: Vespidae) in Central Amazon. Austral Entomol. 2018;58(3):657-65.

23. Basset Y, Novotny V, Miller SE, Kitching RL. Arthropods of Tropical Forests: Spatio-Temporal Dynamics and Resource Use in the Canopy. 1st eds. Basset Y, Novotny V, Miller SE, Kitching RL, editors. Cambridge University Press, Cambridge; 2003.

24. Basset Y, Lamarre GPA. Toward a world that values insects. Sci (80-). 2019;364(6447):1230-1.

25. González HD, Ruíz DB. Los braconidos (Hymenoptera: Braconidae) como grupo parametro de biodiversidad en las selvas deciduas del tropico: una discusion acerca de su posible uso. Acta zoológica Mex. 2000;(79):43-56.

26. Sharkey M, Dangerfield P, Fernández-Triana J, Kittel R, Kula R, Marsh P, et al. Manual of the New World Genera of the Family Braconidae (Hymenoptera). 2nd ed. Wharton R, Marsh P, Sharkey M, editors. Annals of the Entomological Society of America. Washington, DC: The International Society of Hymenopterists; 1997. 
27. Whitfield JB. Estimating the age of the polydnavirus/braconid wasp symbiosis. Proc Natl Acad Sci. 2002;99(11):7508-13.

28. Wright SJ, Muller-Landau HC. The future of tropical forest species. Biotropica. 2006;38(3):287-301.

29. MIAMBIENTE. Áreas protegidas y Vida Silvestre. Parque Natural Metropolitano [Internet]. 2017. Available from: http://www.miambiente.gob.pa/index.php/sistema-nacional-de-areas-protegidassinap.

30. Pinilla ELG. Old north american military bunkers located in the corners of the Panama Canal for tourist purposes. Contact. 2021;1:60-77.

31. Correa M, Stapf M, DeSedas A, Hernández F, Carranza R. Árboles y Arbustos del Parque Natural Metropolitano, Panamá. 1a ed. Morales FJ, editor. Santo Domingo de Heredia: Instituto Nacionalde Biodiversidad, INBio; 2010.

32. Townes H. A light-weight malaise trap. Ent News. 1972;83:239-47.

33. Marchiori $\mathrm{CH}$, Penteado-Dias AM. Braconidae (Hymenoptera: Ichneumonoidea) Collected in a Native Forest Area in Itumbiara, Goiás, Brazil. Scielo. 2002;647-9.

34. Querino R, Couceiro S, Queiroz L, Penteado-Dias A. The spatial distribution of Hymenoptera parasitoids in a forest reserve in Central Amazonia, Manaus, AM, Brazil. Braz J Biol. 2011;71(4):86571.

35. An T, Belokobylskij SA, Kim H, Kim K, Seo H, Ku D. New faunistic data on the family Braconidae (Hymenoptera) from Korea. J Asia-Pacific Biodivers. 2014;7:489-92.

36. Reséndiz-Flores A, Nunes JF, García-Paris, Zaldivar-Riverón A. Six new species of the parasitoid wasp genus Notiospathius (Hymenoptera: Braconidae: Doryctinae) from Mexico. Rev Mex Biodivers. 2014;85:391-401.

37. Rodriguez-Mota AJ, Ruiíz-Cancino E, Ivanovich-Khalaim A, Coronado-Blanco JM, Treviño-Carreón J. Diversidad de Ichneumonidae (Hymenoptera) en un bosque de Pinus spp. y Juniperus flaccida en Jaumave, Tamaulipas, México. Rev Mex Biodivers. 2015;86:972-80.

38. Basset Y, Springate ND, Aberlenc HP, Delvare G. A review of mehtods for sampling arthropods in tree canopies. In: Canopy Arthropods. Chapman \& Hall; 1997. pp. 27-52.

39. Oliver I, Beattie AJ. Invertebrate morphospecies as surrogates for species: A case study. Conserv Biol. 1996;10(1):99-109.

40. Aguilar A, Brothers DJ, Amarante S, Buffington M, Arias-Penna D, Campos D, et al Introducción a los Hymenoptera de la Región Neotropical. Fernández F, Sharkey MJ, editors. Vol. 53. 2006. 93-114 p.

41. San Vicente MG. Índices de fragmentación y conectividad para el indicador de biodiversidad y paisaje de la Comunidad Autónoma del País Vasco. 2003.

42. Statsoft. STATISTICA [Internet]. 2016. Available from: http://www.statsoft.com/Products/STATISTICA.

43. Addinsoft. XLStat statistical and data analysis solution [Internet]. New York, USA; 2021. Available from: https://www.xlstat.com. 
44. Diserud OH, Odegaard F. A multiple-site similarity measure. Biol Lett. 2007;3:20-2.

\section{Figures}

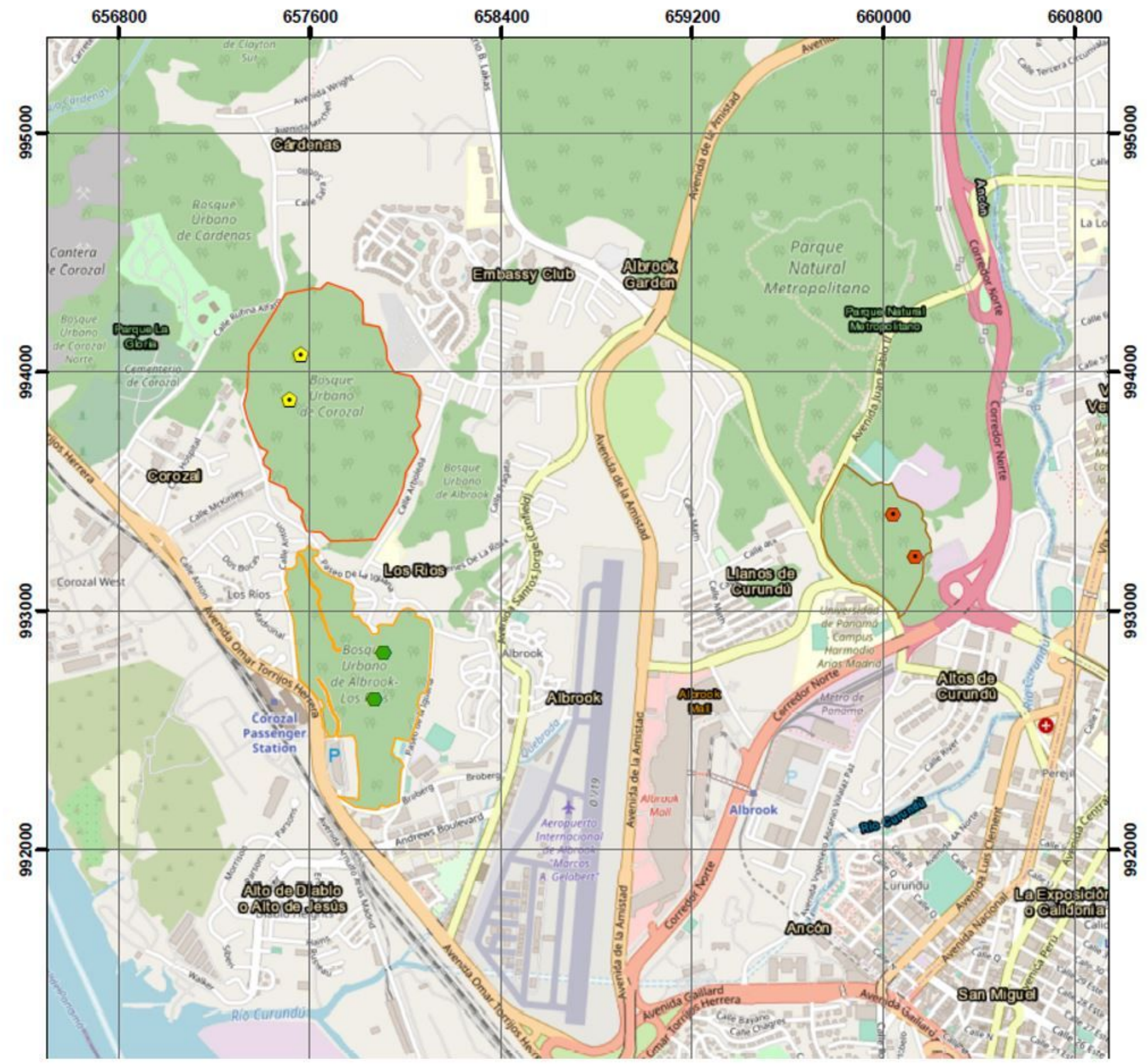

Figure 1

Map of the Pacific Basin of the Panama Canal where the habitat fragments studied in lowland tropical forests of Panama are located: Corozal (COR), Albrook (ALB) and Metropolitan Natural Park (PNM) 


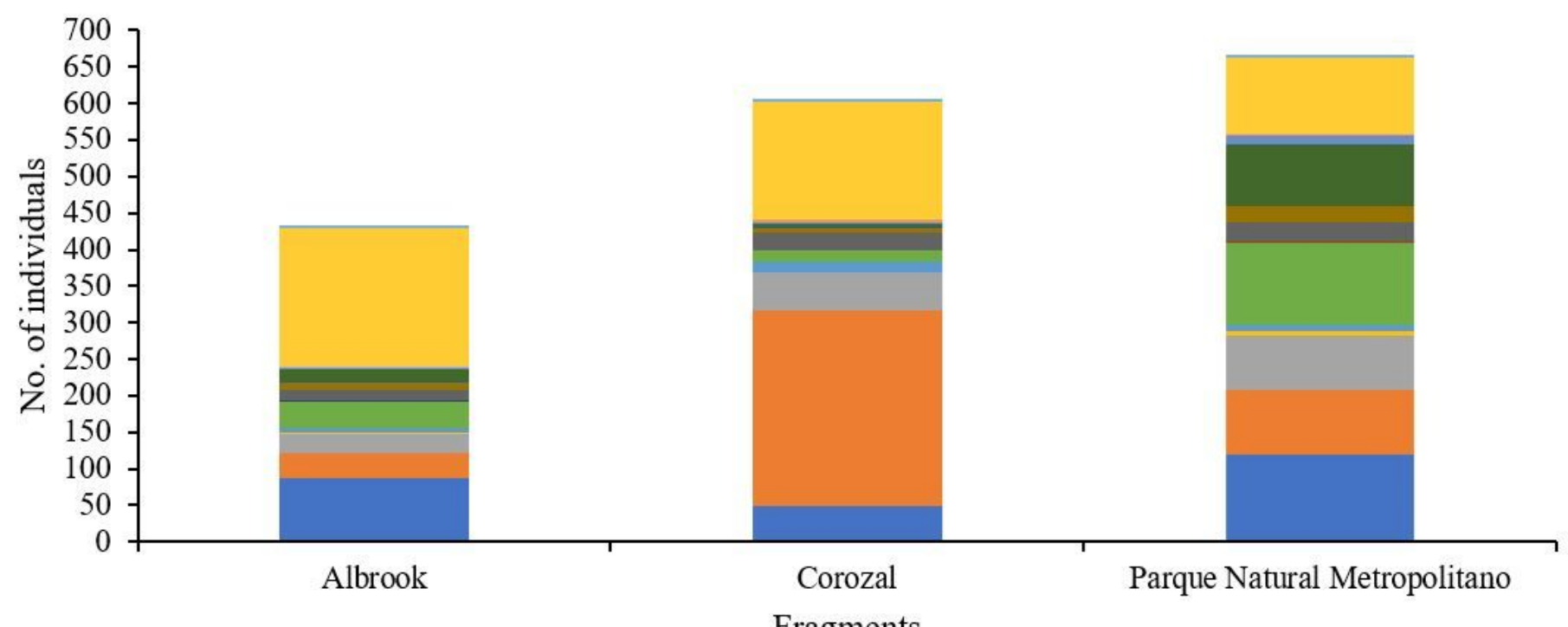

Fragments

\begin{tabular}{|c|c|c|c|c|c|}
\hline - Adeliinae & = Alysiinae & = Aphidiinae & Braconinae & - Cheloninae & - Doryctinae \\
\hline Euphorinae & - Helconinae & - Hormiinae & Ichneutinae & - Meteorinae & Microgastrinae \\
\hline Miracinae & Opiinae & Rogadinae & -Silgophinae & & \\
\hline
\end{tabular}

\section{Figure 2}

Variation in individual abundance of braconid wasp in the three habitat fragments studied in lowland tropical forests of Panama. Each panel shows data for a habitat fragment and is grouped by subfamily. Stacked bar plots show the dominant subfamilies within each habitat fragment 


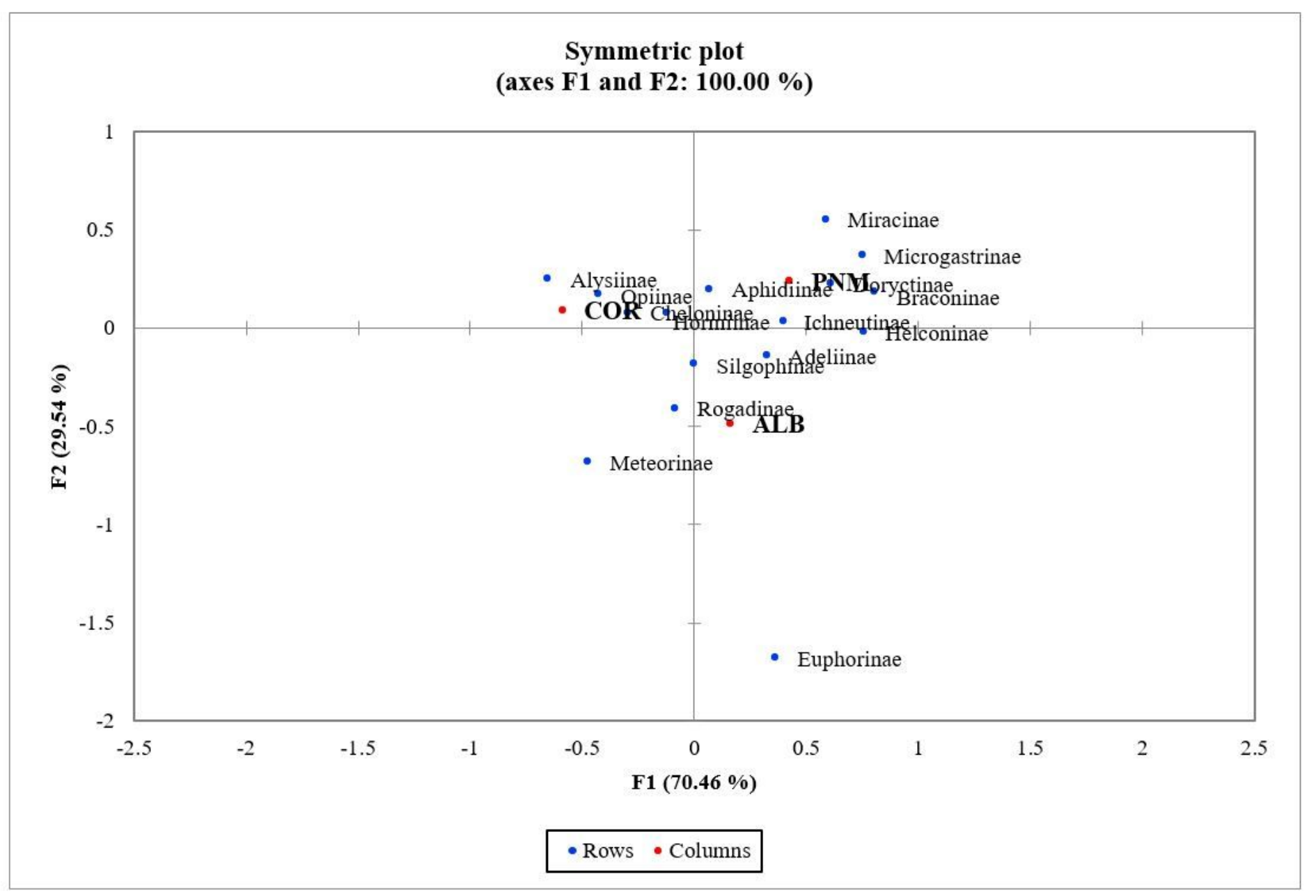

\section{Figure 3}

Correspondence analysis (CA) to compare the similarity of braconid wasp communities between habitat remnants of Corozal (COR), Albrook (ALB) and Metropolitan Natural Park (PNM). The two replicates of each habitat remnant are enveloped to make similarities among habitat remnants more apparent 


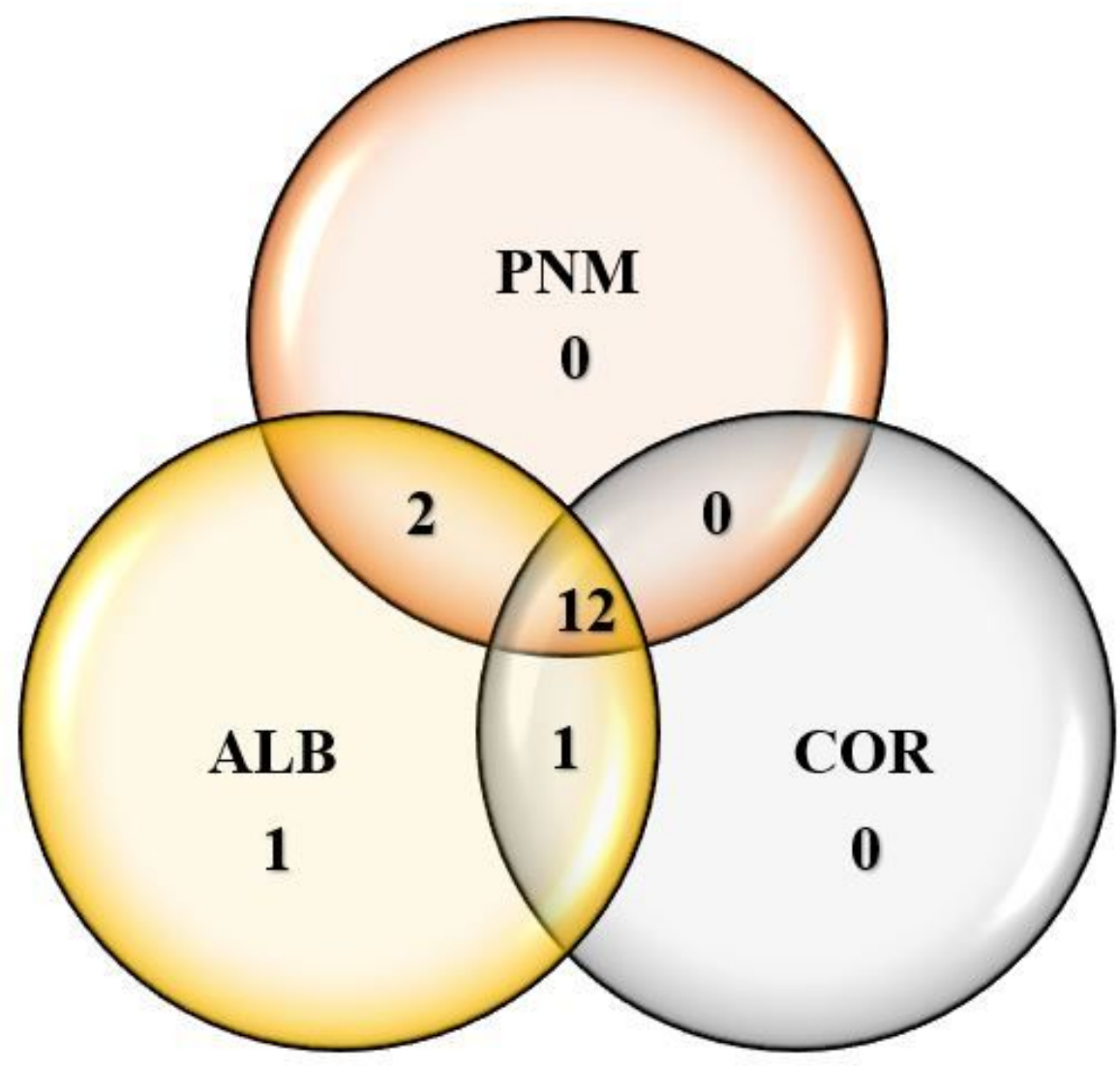

Figure 4

Venn diagram of the number of shared subfamilies of braconid wasps in the three fragments studied in lowland tropical forests of Panama: Corozal (COR), Albrook (ALB) and Metropolitan Natural Park (PNM). Of the 16 subfamilies, 12 were shared between the three habitat fragments studied 


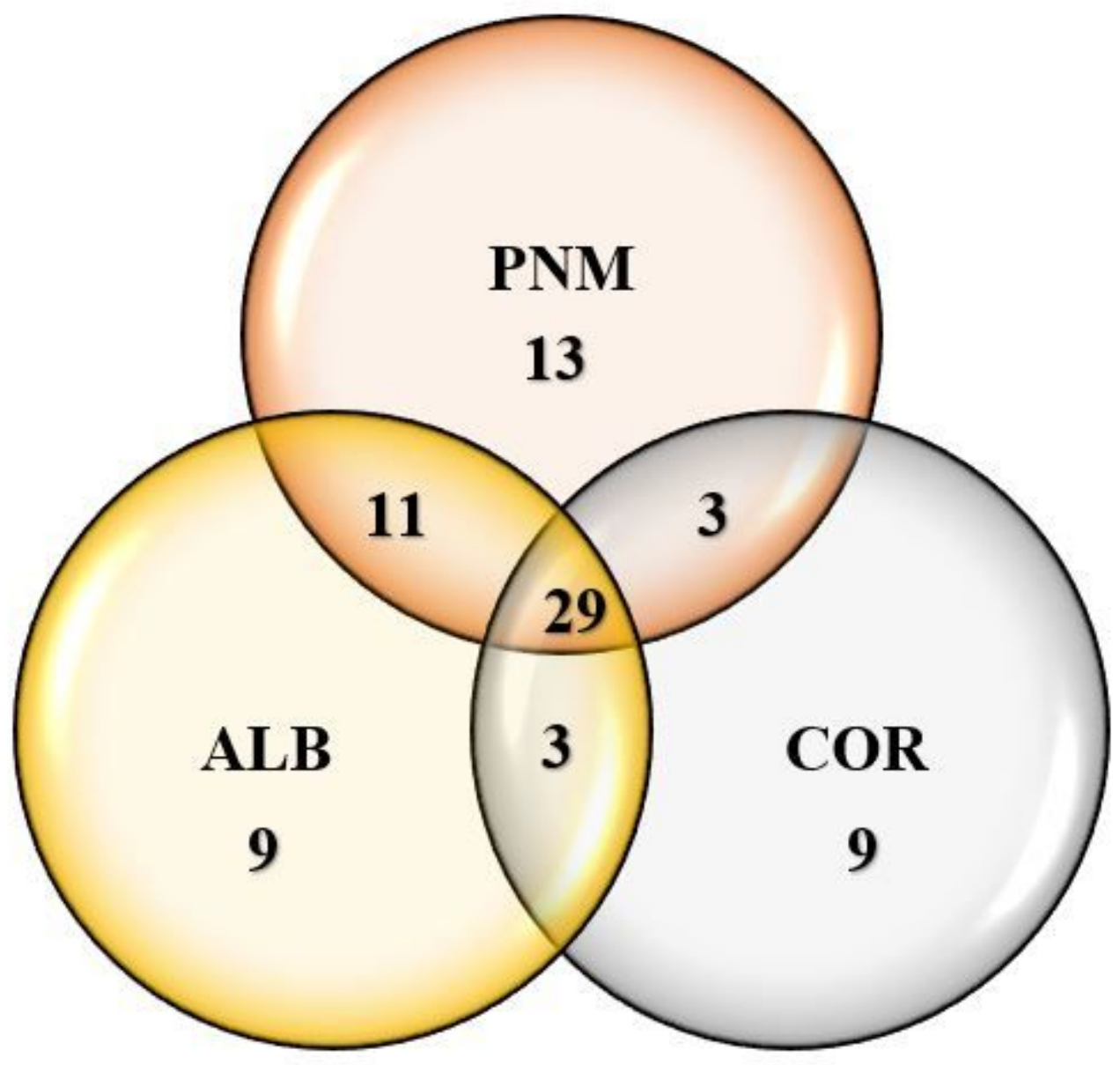

Figure 5

Venn diagram of the number of shared morphospecies of braconid wasps in the three fragments studied in lowland tropical forests of Panama: Corozal (COR), Albrook (ALB) and Metropolitan Natural Park (PNM). Of the 77 morphospecies, 29 were shared between the three habitat fragments studied 


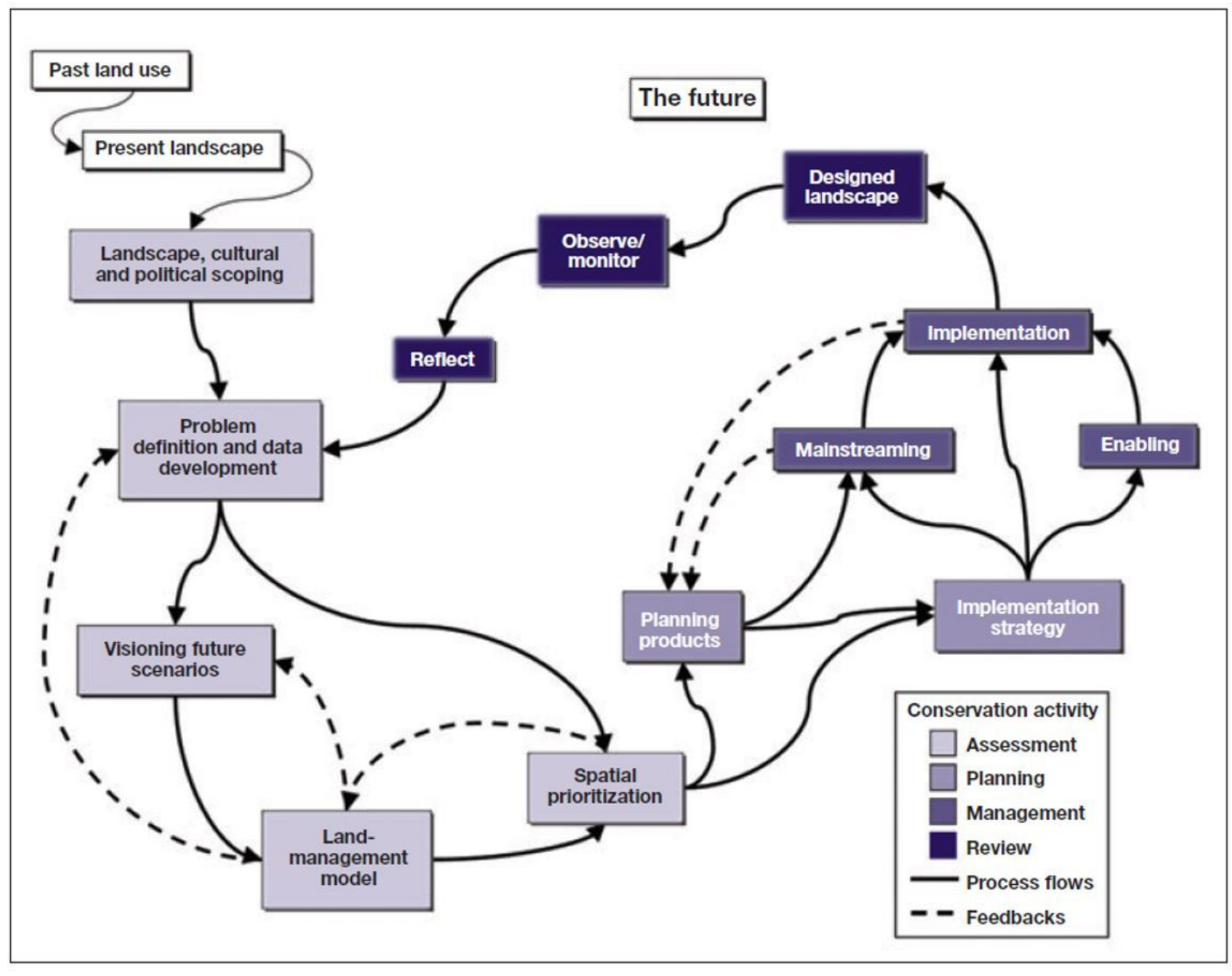

Figure 6

Operational model for conservation planning, incorporating assessment, and management phases (Grantham et al. 2010; Knight et al. 2006) 